\title{
COMMENTARY
}

\section{Biowaiver Monographs for Immediate Release Solid Oral Dosage Forms: Ethambutol Dihydrochloride}

\author{
C. BECKER, ${ }^{1}$ J.B. DRESSMAN, ${ }^{1}$ G.L. AMIDON ${ }^{2}$ H.E. JUNGINGER, ${ }^{3}$ S. KOPP, ${ }^{4}$ K.K. MIDHA, ${ }^{5}$ \\ V.P. SHAH, ${ }^{6}$ S. STAVCHANSKY, ${ }^{7}$ D.M. BARENDS ${ }^{8}$ \\ ${ }^{1}$ Institute of Pharmaceutical Technology, J.W. Goethe University, Frankfurt am Main, Germany \\ ${ }^{2}$ College of Pharmacy, University of Michigan, Ann Arbor, Michigan \\ ${ }^{3}$ Faculty of Pharmaceutical Sciences, Naresuan University, Phitsanulok, Thailand \\ ${ }^{4}$ World Health Organization, Geneva, Switzerland \\ ${ }^{5}$ University of Saskatchewan, Saskatoon, Saskatchewan, Canada \\ ${ }^{6}$ International Pharmaceutical Federation FIP, Den Haag, The Netherlands \\ ${ }^{7}$ Division of Pharmaceutics, College of Pharmacy, University of Texas at Austin, Austin, Texas \\ ${ }^{8}$ RIVM - National Institute for Public Health and the Environment, Bilthoven, The Netherlands
}

Received 7 February 2007; accepted 24 April 2007

Published online in Wiley InterScience (www.interscience.wiley.com). DOI 10.1002/jps.21061

\begin{abstract}
Literature data relevant to the decision to allow a waiver of in vivo bioequivalence (BE) testing for the approval of immediate release (IR) solid oral dosage forms containing ethambutol dihydrochloride as the only active pharmaceutical ingredient (API) are reviewed. Ethambutol dihydrochloride is a Biopharmaceutics Classification System (BCS) Class III drug with permeability properties approaching the border between BCS Class I and III. BE problems of ethambutol formulations containing different excipients and different dosages forms have not been reported and hence the risk of bioinequivalence caused by excipients is low. Ethambutol has a narrow therapeutic index related to ocular toxicity. However, as long as the prescribers' information of the test product stipulates the need for regular monitoring of ocular toxicity, the additional patient risk is deemed acceptable. It is concluded that a biowaiver can be recommended for IR solid oral dosage forms provided that the test product (a) contains only excipients present in ethambutol IR solid oral drug products approved in ICH or associated countries, for instance as presented in this paper, (b) complies with the criteria for "very rapidly dissolving" and (c) has a prescribers' information indicating the need for testing the patient's vision prior to initiating ethambutol therapy and regularly during therapy. (c) 2007 Wiley-Liss, Inc. and the American Pharmacists Association J Pharm Sci 97:1350-1360, 2008
\end{abstract}

Keywords: absorption; Biopharmaceutics Classification System (BCS); ethambutol; permeability; regulatory science; solubility

This paper reflects the scientific opinion of the authors and not the policies of regulating agencies.

A project of the International Pharmaceutical Federation FIP, Groupe BCS, http://www.fip.org/bcs.
Correspondence to: D.M. Barends (Telephone: +31-302744209; Fax: +31-30-2744462; E-mail: Dirk.Barends@RIVM.nl)

Journal of Pharmaceutical Sciences, Vol. 97, 1350-1360 (2008) (C) 2007 Wiley-Liss, Inc. and the American Pharmacists Association 


\section{INTRODUCTION}

A biowaiver monograph of ethambutol dihydrochloride based on literature data together with some additional experimental data is presented. The risks of basing a bioequivalence (BE) assessment on in vitro rather than in vivo study results for the approval of new immediate release (IR) solid oral dosage forms containing ethambutol dihydrochloride ("biowaiving"), including both reformulated products and new multisource products, are evaluated under consideration of its biopharmaceutical and clinical properties. This evaluation refers to drug products containing ethambutol dihydrochloride as the only active pharmaceutical ingredient (API) and not its combination products.

The purpose and scope of this series of monographs have been previously discussed. ${ }^{1}$ Summarized in few words, the aim is to evaluate all pertinent data available from literature sources for a given API to assess the risks associated with a biowaiver. For these purposes, risk is defined as the probability of an incorrect biowaiver decision as well as the consequences of the decision in terms of public health and individual patient risks. On the basis of these considerations, a recommendation can be made as to whether a biowaiver is advisable or not. This systematic approach to recommend or advise against a biowaiver decisions is referred to in the recently published World Health Organization (WHO) Guideline. ${ }^{2}$ Biowaiver monographs have already been published for acetaminophen (INN: paracetamol), ${ }^{3}$ amitriptyline, ${ }^{4}$ atenolol, ${ }^{1}$ chloroquine, ${ }^{5}$ cimetidine ${ }^{6}$ ibuprofen, ${ }^{7}$ isoniazid, ${ }^{8}$ prednisolone, ${ }^{9}$ prednisone,${ }^{10}$ propranolol, ${ }^{1}$ ranitidine,${ }^{11}$ and verapamil. ${ }^{1}$ They are also available online at http:// www.fip.org/bcs.

\section{EXPERIMENTAL}

Literature data was assessed from PubMed, ${ }^{12}$ PubChem, ${ }^{13}$ Medicines Complete, ${ }^{14}$ WHO search engine WHOLIS, ${ }^{15}$ the BIAM, ${ }^{16}$ ROTE LISTE, ${ }^{17}$ and VIDAL $^{18}$ databases. Key words used for searching were: ethambutol, bioequivalence, bioavailability, biowaiver, solubility, permeability, dissolution, tuberculosis, excipient, toxicity, polymorphism, and pharmacokinetics.

\section{GENERAL CHARACTERISTICS}

\section{Name}

Ethambutol (INN) dihydrochloride; ${ }^{19,20}$ ethambutol hydrochloride (INNM); ${ }^{19,20}$ (+)-(S,S)-2,2'-(ethylenediimino)di-1-butanol dihydrochloride;

$\left[\mathrm{S}-\left(\mathrm{R}^{*}, \mathrm{R}^{*}\right)\right]-2,2^{\prime}$-(1,2-ethanediyldiimino)bis[1-

butanol] dihydrochloride. ${ }^{19,20}$

The structure of ethambutol dihydrochloride is shown in Figure 1.

\section{Therapeutic Indications}

Ethambutol is one of the key APIs used in the combination treatment of tuberculosis recommended by the WHO. ${ }^{21}$ The standard regime currently calls for an initial therapy for 2 months with isoniazid, rifampicin, pyrazinamide and ethambutol, followed by a continuation phase of 4 months comprising isoniazid and rifampicin. Ethambutol dihydrochloride is added to the combination of the three more powerful antibiotics to prevent the emergence of resistant bacilli. ${ }^{21}$ Ethambutol is also effective against infections caused by mycobacterium avium complex, mycobacterium bovis, and other atypical mycobacteria. ${ }^{22}$

\section{Therapeutic Index and Toxicity}

WHO ${ }^{21}$ the Martindale, ${ }^{22}$ and the British and American Thoracic Society recommend doses of 15 (15-20) $\mathrm{mg} / \mathrm{kg} /$ day, $15 \mathrm{mg} / \mathrm{kg} /$ day, and $15-25 \mathrm{mg} / \mathrm{kg} /$ day, respectively. The most serious major adverse drug reaction (ADR) in the treatment with ethambutol dihydrochloride is visual impairment, including irreversible blindness, due to drug-induced optic neuritis. ${ }^{23-25}$ The toxicity is dose related. At doses higher than $30 \mathrm{mg} / \mathrm{kg} /$ day the incidence of optic neuropathy increases to $8 \%$. However, this ADR rarely occurs at $15 \mathrm{mg} / \mathrm{kg} /$ day. ${ }^{17,26}$ Thus, the margin between the therapeutic doses and doses at which the risk for this $\mathrm{ADR}$ increases, is narrow. According to the

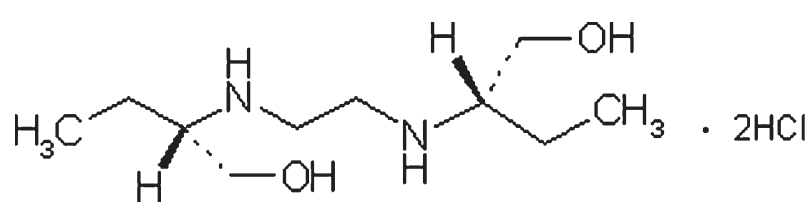

Figure 1. Structure of ethambutol dihydrochloride, $M_{\mathrm{r}} 277.23$. 
current WHO guideline, the onset of this ADR should be managed by immediate interruption of ethambutol treatment. ${ }^{21}$ Toman's Tuberculosis ${ }^{26}$ recommends that a basic examination should be conducted before starting treatment with ethambutol. Additionally, patients treated with ethambutol should be educated to detect and report changes in vision and be regularly monitored for visual acuity and color vision. ${ }^{22,27}$ Ethambutol should be used with caution in patients with ocular defects (e.g., cataracts, recurrent ocular inflammatory conditions, diabetic retinopathy) and is contraindicated in patients with optic neuritis since in these cases visual changes are difficult to detect or evaluate. ${ }^{28,29}$ For patients with ocular defects the benefits of ethambutol therapy should be carefully weighed against possible ocular adverse effects. Most drug products having a marketing authorization (MA) have a prescribers' information, the Summary of Product Characteristics (SmPCs), containing appropriate cautionary statements as well as instructions for monitoring of vision.

\section{CHEMICAL PROPERTIES}

\section{Stereoisomers and Polymorphs}

All marketed products employ the therapeutically active stereoisomer (S,S)-ethambutol as the dihydrochloride salt. Therefore, the official national and pharmacopoeial name: ethambutol hydrochloride $^{19,20}$ derived from the INN might be somewhat misleading to those accustomed to standard chemical nomenclature.

Four polymorphic forms have been reported, but only form II is used in drug formulations. ${ }^{30}$

\section{Solubility}

Ethambutol dihydrochloride is readily soluble ${ }^{31}$ indicating that at least $1000 \mathrm{mg}$ is soluble in $1 \mathrm{~mL}$ of water at room temperature. ${ }^{19,32,33}$ Experimental equilibrium solubility data of ethambutol dihydrochloride in compendial standard buffers $\mathrm{pH} 1.2,4.5$, and 6.8 at $37^{\circ} \mathrm{C}$ were recently obtained using the standard shake-flask method over $48 \mathrm{~h} . *$ The $\mathrm{pH}$ of the buffers was monitored and readjusted when necessary to the initial $\mathrm{pH}$

\footnotetext{
*Experiments performed at the Institute of Pharmaceutical Technology, J.W. Goethe University, Frankfurt am Main, Germany.
}

values. A validated photometric method previously described in the literature was used for quantification. ${ }^{33}$ The literature data and new experimental solubility data are summarized in Table 1.

\section{Partition Coefficient $(\log P)$}

A $\log P$ of 0.4 is reported for the system octanol/ water, however no detailed information about the test conditions for example, temperature, $\mathrm{pH}$, etc. was provided. ${ }^{32}$ A computed $X \log P$ of -0.344 is indicated in PubChem. ${ }^{13}$ Kasim et al. ${ }^{34}$ obtained a $\log P$ of 0.06 and $C \log \mathrm{P}^{\circledR}$ of 0.12 , respectively, by a calculation method based on atomic contributions to lipophilicity and by the $\mathrm{C} \log \mathrm{P}^{\circledR}$ program.

$\mathrm{p} K_{\mathrm{a}}$

Ethambutol is a weak base. At $20^{\circ} \mathrm{C}, \mathrm{p} K_{\mathrm{a}}$ values of $6.3^{22}$ and 6.6 for the lower $\mathrm{p} K_{\mathrm{a} 1}$ and $9.5^{22,31}$ for the higher $\mathrm{p} K_{\mathrm{a} 2}$ were reported. Separately, a $\mathrm{p} K_{\mathrm{a}}$ value of $6.6^{31}$ was obtained by a titration technique.

\section{Dosage form Strengths}

The WHO Essential Medicines List (EML) lists ethambutol dihydrochloride tablet strengths from 100 to $400 \mathrm{mg}$. ${ }^{35}$ Single API dosage forms with a MA in Germany (DE), Finland (FI), France (FR), The Netherlands (NL), and Sweden (SE) contain 100-500 mg. In the United States, MAs exist for strengths in the range from 100 to $400 \mathrm{mg} .{ }^{36}$

\section{PHARMACOKINETIC PROPERTIES}

\section{Permeability and Absorption}

No studies investigating in situ or ex vivo intestinal permeability or Caco- 2 cell permeability of ethambutol dihydrochloride were identified. It was reported that ethambutol dihydrochloride is not fully absorbed from the gastro-intestinal (GI) tract and may exhibit unusual pharmacokinetics as a result of transport via the bile duct and/or chelating in the GI tract. ${ }^{37}$

In an early study, the urinary recovery in patients with tuberculosis was compared to healthy volunteers. ${ }^{38}$ After 24 h, $45 \%$ of the dose 
Table 1. Literature Data and New Experimental Data for the Solubility of Ethambutol Dihydrochloride and the Corresponding D/S Ratios for Two Tablet Strengths

\begin{tabular}{|c|c|c|c|c|c|}
\hline \multirow[b]{2}{*}{ Medium } & \multirow[b]{2}{*}{$\mathrm{pH}$} & \multirow[b]{2}{*}{ Temperature $\left({ }^{\circ} \mathrm{C}\right)$} & \multirow[b]{2}{*}{ Solubility $(\mathrm{mg} / \mathrm{mL})$} & \multicolumn{2}{|c|}{$\mathrm{D} / \mathrm{S}$ Ratio $(\mathrm{mL})^{a}$} \\
\hline & & & & $400 \mathrm{mg}$ Tablet $^{b}$ & $500 \mathrm{mg}$ Tablet $^{c}$ \\
\hline \multicolumn{6}{|c|}{ New experimental data } \\
\hline Water & & 37 & 649 & 0.62 & 0.77 \\
\hline $\mathrm{SGF}_{\mathrm{sp}}$ & 1.2 & 37 & 771 & 0.52 & 0.65 \\
\hline Phosphate buffer & 4.5 & 37 & 706 & 0.57 & 0.71 \\
\hline $\mathrm{SIF}_{\mathrm{sp}}$ & 6.8 & 37 & 747 & 0.54 & 0.67 \\
\hline \multicolumn{6}{|l|}{ Pharmacopoeial data } \\
\hline Water & & Not defined, about $25^{\circ} \mathrm{C}$ & $\approx 1000$ & $\sim 0.5$ & $\sim 0.4$ \\
\hline
\end{tabular}

was found in the urine of the healthy volunteers, compared to $62 \%$ in the patient population. However, these values were based on microbiologic assays and consequently inactive metabolites of ethambutol were not detected. ${ }^{39}$ Dume et al. ${ }^{40}$ reported a urinary recovery of $46 \%$ after oral administration to healthy volunteers. In a later study, Peets et al. $^{41}$ administered ${ }^{14} \mathrm{C}$ radiolabelled ethambutol orally to three patients with advanced, drug-resistant tuberculosis. Urine, feces, and plasma were sampled. In the urine, 54-61\% was recovered after $24 \mathrm{~h}$ and $67-74 \%$ after $144 \mathrm{~h}$. After $48 \mathrm{~h}, 12-19 \%$ of the dose was found in the feces. An additional intravenous (i.v.) dose was also administered to a female patient in this study, enabling the urinary excretion after oral and i.v. dosing to be compared: after i.v. administration, $81 \%$ was excreted in the urine within $48 \mathrm{~h}$ compared to only $67 \%$ after oral intake. Based on these results, the availability of the oral dose is calculated to be $83 \%$. Additionally, only $1 \%$ of the i.v. dose was recovered in the feces, compared to $18 \%$ after oral administration. It can therefore be assumed that about $20 \%$ of an oral dose are not absorbed from the GI tract. ${ }^{41}$ Lee et al. ${ }^{42,43}$ reported urinary recoveries of an aqueous solution and a tablet formulation versus i.v. in six healthy volunteers. After $72 \mathrm{~h}, 79 \%$ of the i.v. dose but only 61\% (tablet) and 63\% (aqueous solution) of the oral doses had been recovered in the urine. ${ }^{43}$ The absolute BAs were calculated as $77 \%$ (tablet) and $80 \%$ (solution). ${ }^{37}$ Kleber et al. ${ }^{44}$ investigated the influence of gastric surgery on the absorption of ethambutol and reported an absolute BA of $89 \%$ in partially gastrectomized patients. A microbiological assay technique, unable to detect nonactive metabolites, was used for quantification.

In an early study, Place et al. ${ }^{38,39}$ determined the dose-dependency of ethambutol absorption, showing that the serum level increased proportionally to the dose over the range of $4-50 \mathrm{mg} / \mathrm{kg}$.

\section{Distribution}

Ethambutol is distributed into most body tissues including the lung, kidneys and saliva. It penetrates inflamed meninges $(10-50 \%)$ to reach therapeutic levels in the CSF. ${ }^{22}$ Analysis of the erythrocytes indicated accumulation of the API in erythrocytes. ${ }^{39}$ This finding is consistent with the work of Lee et al., ${ }^{37}$ who found a 1.2- to 2.6-fold higher concentration of ethambutol in erythrocytes than in the plasma. In subsequent studies, Place et al. $^{39}$ and Lee et al. ${ }^{43}$ observed a concentration ratio of ethambutol in erythrocytes to plasma of 1.1-1.6 and 2, respectively. In an early study, Lee et al. ${ }^{37}$ determined the plasma protein binding by equilibrium dialysis and ultra filtration against buffer $\mathrm{pH} 7.4$ for $4 \mathrm{~h}$ and obtained a value of approximately 20-30\%. Plasma protein binding values of $6-30 \%$ have also been reported in healthy subjects and in patients with tuberculosis. ${ }^{45}$

\section{Metabolism and Excretion}

About 8-15\% of the administered ethambutol dose is metabolized in the liver to inactive metabolites, with small interpatient variation; the extent of metabolism is independent of the route of 
administration. ${ }^{39,41,46}$ Two metabolites have been identified: an aldehyde intermediate in the oxidation process and a second, more hydrophilic dicarboxylic acid derivate, 2,2'-(ethylenediimino)di-butyric acid. Chronic administration does not change the metabolic characteristics of ethambutol. ${ }^{38}$

Elimination half-lives reported for ethambutol range between 1.2 and $4.2 \mathrm{~h}$, depending on the study population, detection method, etc. ${ }^{38,40,47}$ Lee et al., ${ }^{37,43}$ measured a three to five times higher renal clearance than the creatine clearance after i.v. administration, indicating an active secretion mechanism. Because of the high renal clearance as well as the recovery of a large fraction of the dose intact in the urine, changes in the renal function can alter the kinetics of the antibiotic. These effects were subsequently demonstrated by the same authors in study in a renal insufficient patient. $^{43}$

\section{Food and Excipient Interactions}

Peloquin et al. ${ }^{48}$ investigated the pharmacokinetics of ethambutol dihydrochloride in healthy volunteers under fasted conditions, after a highfat standard FDA breakfast and after the administration of an aluminum magnesium hydroxide combination antacid. Food did not significantly affect $C_{\max }$ and AUC compared to the fasted state, whereas the antacid preparation reduced $C_{\max }$ by $29 \%$ and AUC by $10 \% .{ }^{49}$ These findings are in line with the work of Mattila et al. ${ }^{49}$ and Ameer et al. ${ }^{50}$ who also investigated the influence of food and antacids on the absorption of ethambutol. In separate studies, ethambutol has been shown to form chelates with di- and trivalent cations. ${ }^{51}$ The authors subsequently recommended that zinc, copper, or calcium containing preparations, such as antacids or dietary supplements, should be avoided near the time of ethambutol administration. ${ }^{27,28}$

\section{DOSAGE FORM PERFORMANCE}

\section{Bioavailability and Bioequivalence}

Lee et al. ${ }^{37,43}$ compared the BA of a single dose oral aqueous ethambutol solution to an unbroken, commercially available tablet formulation in six fasted healthy volunteers. Plasma and urine samples were collected until $72 \mathrm{~h}$ post treatment. AUCs, urinary recovery and $C_{\text {max }}$ of the tablet and the oral solution tested were not significantly different. ${ }^{42,43}$ The $t_{\max }$ values differed slightly. In a recent in vivo study in 20 healthy volunteers, the $\mathrm{BE}$ of the products EMB-Fatol ${ }^{\mathbb{R}} 400$ and $500 \mathrm{mg}$, both marketed in $\mathrm{DE}$, were compared to aqueous oral solutions containing the same dose. ${ }^{27}$ For both strengths, AUC, $C_{\max }$, and $t_{\max }$ of the test formulations were not significantly different compared to the oral solutions. No in vivo $\mathrm{BE}$ studies comparing solid oral ethambutol dihydrochloride formulations from different manufacturers could be identified, but some in vivo $\mathrm{BE}$ studies comparing fixed dose combinations to formulations containing ethambutol dihydrochloride as the only API in healthy volunteers have been reported. The BE of the products under investigation was confirmed with respect to ethambutol. However, these studies focused on rifampicin and detailed information about the composition of the formulations, etc. was not provided. ${ }^{52-55}$

\section{Excipients}

In vitro, it was demonstrated that ethambutol can form chelates with di- and trivalent metal cations, present in fillers, binders, and lubricants. ${ }^{51}$ Table 2 shows the excipients present in ethambutol dihydrochloride IR solid oral drug products with a MA in DE, FI, FR, NL, and SE. It can be inferred that these drug products successfully passed an in vivo BE study. In contrast to some other APIs, ethambutol has not been exempted from in vivo $\mathrm{BE}$ testing in $\mathrm{DE}{ }^{56,57}$ In Table 2 the amounts of the various excipients found in single API ethambutol products, along with the ranges specified by the FDA for oral drug products in general, are given.

\section{Dissolution}

The current USP specifies dissolution of $\leq 75 \%$ (Q) within $45 \mathrm{~min}$ in $900 \mathrm{~mL}$ of water in the basket apparatus at a rotation speed of $100 \mathrm{rpm} .{ }^{58}$ Comparative in vitro dissolution studies of ethambutol dihydrochloride drug products could not be identified in the literature. The dissolution behavior of an amount of ethambutol dihydrochloride powder equivalent to the highest strength of the WHO EML was experimentally* assessed according to the WHO requirements for $\mathrm{BE}^{2}$ Within $10 \mathrm{~min}$, almost $100 \%$ was dissolved in USP $\mathrm{SGF}_{\mathrm{sp}} \mathrm{pH} 1.2$, in phosphate buffer $\mathrm{pH} 4.5$, and in USP $\mathrm{SIF}_{\mathrm{sp}} \mathrm{pH} 6.8$. 
Table 2. Excipients* Present in Ethambutol Hydrochloride IR Solid Oral Drug Products with a Marketing Authorization (MA) in Germany (DE), Finland (FI), France (FR), The Netherlands (NL), and Sweden (SE), and the Minimal and Maximal Amount of that Excipient Present Pro-Dosage Unit in Solid Oral Drug Products with a MA in the United States

\begin{tabular}{lcc}
\hline & $\begin{array}{c}\text { Country, Products Containing } \\
\text { Named Excipient (See Footnote for } \\
\text { Product Names) }\end{array}$ & $\begin{array}{c}\text { Range Present in } \\
\text { Solid Oral Dosage Forms with } \\
\text { a MA in the USA (mg) }\end{array}$ \\
\hline Calcium hydrogen phosphate & $\mathrm{DE}^{1,2}$ & $104-850$ \\
Castor oil & $\mathrm{FI}^{3}$ & $0.03-3.1$ \\
Cellulose & $\mathrm{DE}^{1,2,4}, \mathrm{FI}^{3}$ & $4.6-1385^{a}$ \\
Cellulose acetate phthalate & $\mathrm{FI}^{3}$ & $2.4-47.5$ \\
Copovidone & $\mathrm{DE}^{1,2,4}$ & $86-500$ \\
Croscarmellose sodium & $\mathrm{DE}^{1,2,4}$ & $2-180$ \\
Crospovidone & $\mathrm{DE}^{1,2,4}$ & $4.4-792^{a}$ \\
Gelatine & $\mathrm{DE}^{5,6}, \mathrm{FR}^{7,8}, \mathrm{NL}^{9}, \mathrm{SE}^{10,11}$ & $1-756^{a}$ \\
Glycerol & $\mathrm{F}^{3}$ & $0.14-198^{b}$ \\
Hypromellose & $\mathrm{DE}^{1,2,4-6}$ & $0.8-80$ \\
Lactose & $\mathrm{DE}^{1,2,4}$ & $23-1020^{a}$ \\
Light liquid paraffin & $\mathrm{DE}^{5,6}, \mathrm{FR}^{8}$ & $0.8-1474^{a}$ \\
Liquid paraffin & $\mathrm{NL}^{9}, \mathrm{FR}^{7}$ & $1.3-50$ \\
Macrogol & $\mathrm{DE}^{1,2,4}, \mathrm{FI}^{3}, \mathrm{FR}^{7}$ & $0.12-500^{\alpha}$ \\
Magnesium stearate & $, \mathrm{FI}^{3}, \mathrm{FR}^{7,8}, \mathrm{NL}^{9}, \mathrm{SE}^{10,11}$ & $0.9-401^{a}$ \\
Povidone & $\mathrm{DE}^{1,2,4}, \mathrm{FI}^{3}$ & $0.17-75$ \\
Silica & $\mathrm{DE}^{1,2,4} \mathrm{FR}^{7}$ & $0.65-99$ \\
Sodium lauryl sulphate & $\mathrm{DE}^{5,6}$ & $0.65-50$ \\
Sorbitan oleate & $\mathrm{FI}^{3}$ & $0.11-1.7$ \\
Sorbitol & $\mathrm{DE}^{1,2,4}$ & $5-337$ \\
Starch & $\mathrm{FR}^{7}$ & $22-616$ \\
Stearic acid & $\mathrm{DE}^{5,6}, \mathrm{FR}^{8}, \mathrm{NL}^{9}, \mathrm{SE}^{10,11}$ & $0.9-72^{a}$ \\
Sucrose & $\mathrm{DE}^{5,6}, \mathrm{FI}^{3}, \mathrm{FR}^{8}, \mathrm{NL}^{9}, \mathrm{SE}^{10,11}$ & $12-900$ \\
Talc & $\mathrm{DE}^{5,6}, \mathrm{FR}^{8}, \mathrm{NL}^{9}, \mathrm{SE}^{10,11}$ & $3-220^{a}$ \\
\hline
\end{tabular}

Sources of data: DE: http://www.rote-liste.de (assessed 17-08-2006); FI: http://www.nam.fi (assessed 18-08-2006); FR: http:// www.vidal.fr (assessed 23-08-2006); NL: http://www.cbg-meb.nl (assessed 17-08-2006); SE: http://www.lakemedelsverket.se (assessed 18-08-2006); USA: http://www.fda.gov/cder/iig/iigfaqWEB.htm\#purpose (version date: July 2006).

$*$ Colorants, flavors and ingredients present only in the coating and/or the printing ink are not included. Drug products containing more than one API were excluded.

${ }^{a}$ The upper range value reported is unusually high for solid oral dosage forms and the authors question its correctness.

${ }^{b}$ The authors have doubts about the correctness of this data. Such amounts are normally present in soft, but not hard gelatine capsules, as indicated by FDA Inactive Ingredients Database.

${ }^{1}$ EMB-Fatol ${ }^{\mathbb{R}} 100 \mathrm{mg}$ Tabletten (Mono).

${ }^{2}$ EMB-Fatol ${ }^{\circledR}$ 400-500 mg Filmtabletten (Mono).

${ }^{3}$ Oributol ${ }^{\mathrm{R}} 100-500 \mathrm{mg}$ tabletti.

${ }^{4}$ EMB-Fatol ${ }^{\circledR} 250 \mathrm{mg}$ Filmtabletten (Mono).

${ }^{5}$ EMBHefa 400 Filmtabletten (Mono).

${ }^{6}$ Myambutol $^{\mathbb{R}}$ 100-400 mg Filmtabletten (Mono).

${ }^{7}$ DEXAMBUTOL $500 \mathrm{mg}$ cp pelliculé.

${ }^{8}$ MYAMBUTOL $400 \mathrm{mg}$ cp pelliculé séc.

${ }^{9}$ Myambutol, tabletten $400 \mathrm{mg}$.

${ }^{10}$ Myambutol $^{\circledR} 100 \mathrm{mg}$ dragerad tablett.

${ }^{11}$ Myambutol $^{\circledR} 400 \mathrm{mg}$ dragerad tablett.

\section{DISCUSSION}

\section{Solubility}

The solubility values found in the literature were not assessed under conditions specified for the Biopharmaceutics Classification System (BCS) classification. ${ }^{2,59,60}$ Therefore new solubility determinations were carried out. The time-frame for the solubility determination was extended to $48 \mathrm{~h}$, because the equilibrium solubility was not reached within $24 \mathrm{~h}$. The minimum solubility of ethambutol dihydrochloride was about $700 \mathrm{mg} /$ $\mathrm{mL}$. The corresponding Dose/Solubility (D/S) 
ratio, calculated for the highest commercially available tablet strengths on the German market and on the WHO EML, resulted in D/S values of $0.8 \mathrm{~mL}$ or lower in the relevant $\mathrm{pH}$ range, see Table 1.

An API is "highly soluble" if its D/S ratio is below $250 \mathrm{~mL}^{2,59,60}$ Thus, ethambutol dihydrochloride is "highly soluble."

\section{Permeability}

Values range from $77 \%$ to $89 \%$ for the extent of absorption of an oral dose of ethambutol, absolute BA and complete urinary recovery. This is consistent with study results which report that about $20 \%$ of the oral dose is recovered in the feces (compared to only 1\% after i.v. administration) and consequently not absorbed. ${ }^{41}$ However, some of these results are not completely reliable because of the assay technique used: radioactive labeling with an incomplete mass balance ${ }^{41}$ or microbiological assays ${ }^{44}$ which are not sensitive to inactive metabolites. In summary, it can be concluded that the fraction of dose absorbed of the API is in the range $60-80 \%$.

Given the low molecular weight, the high water solubility and the hydrophilic structure of this API, it can be hypothesized that ethambutol is transported by a paracellular mechanism.

Kasim et al. ${ }^{34}$ classified ethambutol dihydrochloride as "poorly permeable" based on in silico correlations of the partition coefficients $\log P$ and $C \log \mathrm{P}^{\circledR}$ to intestinal permeability. However, their classification methodology has only limited predictability. ${ }^{8} \mathrm{Wu}$ et al. ${ }^{61}$ classified ethambutol dihydrochloride in their Biopharmaceutics Drug Disposition Classification System (BDDCS), using elimination and disposition characteristics. Surprisingly, they assigned ethambutol dihydrochloride to BCS Class I, although this API is eliminated renally and mainly unchanged, characteristics that the authors attribute to BCS Class III drugs. Lindenberg et al. ${ }^{62}$ classified ethambutol dihydrochloride as a BCS Class III drug, using literature BA data.

\section{BCS Classification}

Ethambutol dihydrochloride is "highly soluble."2,59,60 Data on its oral absorption and permeability are not fully conclusive but suggest this API to be a BCS Class III drug, with permeability properties approaching the border to BCS Class I.
It should be noted that the cut-off for "highly permeable" varies with regulatory authority. The FDA sets a limit for the fraction of dose absorbed of not less than $90 \%,{ }^{60}$ the EMEA $^{59}$ requires "high permeability" but does not define a limit for the fraction of dose absorbed and the WHO requires not less than $85 \%$ fraction of dose absorbed. ${ }^{2}$

Up to now, the FDA does not accept biowaivers for BCS Class III APIs, which would exclude ethambutol from biowaiving. ${ }^{59,60}$ On the other hand, the recently revised WHO guidance extended the possibility of a biowaiver approval to BCS Class III APIs under certain conditions. ${ }^{2}$ Therefore ethambutol dihydrochloride is a candidate for biowaiving according to the WHO guidance.

\section{Surrogate Techniques for In Vivo Bioequivalence Testing}

Ethambutol dihydrochloride is "highly soluble" and the pure drug shows "very rapid dissolution." Furthermore bioinequivalence of ethambutol dihydrochloride formulations was reported neither in vivo nor in vitro and is unlikely to occur for this very soluble API. Hence, the stricter dissolution methodology for biowaiving of BCS Class III drugs according the WHO Guidance, that is, "very rapid dissolution" over the $\mathrm{pH}$ range of 1.2-6.8, should be capable of detecting poor quality of formulations. ${ }^{2}$ It is noted that the WHO dissolution methodology ${ }^{2}$ uses a $75 \mathrm{rpm}$ rotation speed for the paddle method, whereas the FDA Biowaiver Guideline for the paddle uses $50 \mathrm{rpm} .{ }^{60}$ This increase in rpm was made to reduce the possibility of "coning," which often occurs at $50 \mathrm{rpm}$ and results in an artefactually slow dissolution rate.

A caveat to the use of dissolution tests as surrogates for in vivo $\mathrm{BE}$ testing is that in vitro dissolution tests are not able to detect excipient influences on permeability and/or GI transit time which may cause bioinequivalence.

\section{Risks of Bioinequivalence Caused by Excipients and/or Manufacturing}

Ethambutol was shown to form chelates in vitro, but the magnitude of this phenomenon in vivo appears to be uncertain in the light of commercial products. For instance, the tablet formulation EMB-Fatol ${ }^{\circledR}$, having a MA in DE, contains calcium hydrogen phosphate and no difference in the BA compared to other formulations was 
found. ${ }^{27}$ Furthermore tablet formulations containing ethambutol dihydrochloride as the sole API were found to be bioequivalent to oral solutions in vivo. Also, in vivo $\mathrm{BE}$ studies of ethambutol in fixed dose combinations versus formulations containing ethambutol as the only API, confirmed the BE of the products under investigation. Since no report of a bioinequivalent drug product has appeared in the accessible literature, the risk of bioinequivalence of ethambutol IR dosage forms seems to be low. The risk of bioinequivalence caused by an excipient interaction is further reduced if the test product contains only excipients present in drug products having a MA in an ICH or associated country. ${ }^{63}$ The excipients present in a number of European countries are listed in Table 2.

\section{Patient Risks Associated with Bioinequivalence}

Bioinequivalence of ethambutol IR dosage forms can lead to decreased antituberculosis efficacy on the one hand and to serious, dose-dependent ocular ADRs on the other hand.

In the case of subtherapeutic blood levels, ethambutol dihydrochloride would not fulfill its function in the combination treatment of TB, which is to decrease the emergence of resistance to other components of the multidrug regimen. ${ }^{64}$ However, the risk of bioinequivalence of ethambutol IR dosage forms appears to be relatively low, especially if the test product is formulated only with excipients shown in Table 2 and complies with the criteria for "very rapidly dissolving."

In case of a supra-bioavailable ethambutol product, serious, dose-dependent ocular ADRs could theoretically occur as a consequence of a higher AUC and/or $C_{\max }$ of the test product. However, the therapeutic dose (15-25 mg/kg/day) and the dose at which the risk for this ADR increases, $\leq 30 \mathrm{mg} / \mathrm{kg} /$ day, differ by a factor of two. It seems highly unlikely that the test product would show twice the AUC and/or $C_{\max }$ of a comparator, with which it has been deemed to be pharmaceutically equivalent, especially when both products have been demonstrated to be "very rapidly dissolving." 2 Thus, provided that patients treated with ethambutol containing products are regularly monitored for visual toxicity, the additional risks to the individual patient associated with a biowaiver-based approval can be deemed acceptable. It is noted that most SmPCs for ethambutol products contain such a warning and have instructions for regular ocular monitoring.

When these conditions are fulfilled by the test product, the additional risk associated with a biowaiver-based approval of solid oral ethambutol dihydrochloride IR formulations appears to be acceptable.

\section{CONCLUSIONS}

A biowaiver can be recommended for IR solid oral dosage forms containing ethambutol dihydrochloride provided that the test product (a) contains only excipients present in ethambutol IR solid oral drug products approved in ICH or associated countries, for instance as presented in Table 2, (b) complies with the criteria for "very rapidly dissolving," and (c) has a SmPC indicating the need for visual testing prior to initiating ethambutol therapy and regularly during therapy, including a description of alarming visual symptoms of acute optic neuritis. When not all these conditions are fulfilled, BE should be established in vivo.

\section{ACKNOWLEDGMENTS}

Dr. M. Flegel, F. Riemser Arzneimittel AG, Schiffweiler and Dr. Kunitz, Lungenklinik Heckeshorn, Berlin, both Germany, and Kik Groot, RIVM, are acknowledged for providing literature data, for detailed information of the ADRs of ethambutol, and producing Table 2 , respectively.

\section{REFERENCES}

1. Vogelpoel H, Welink J, Amidon GL, Junginger HE, Midha KK, Moller H, Olling M, Shah VP, Barends DM. 2004. Biowaiver monographs for immediate release solid oral dosage forms based on biopharmaceutics classification system (BCS) literature data: Verapamil hydrochloride, propranolol hydrochloride, and atenolol. J Pharm Sci 93: 1945-1956.

2. WHO. 2006. Proposal to waive in vivo bioequivalence requirements for WHO Model List of Essential Medicines immediate-release, solid oral dosage forms. Technical Report Series, No 937, 40th Report, Annex 8 of WHO Expert committee on specifications for pharmaceutical preparations http://whqlibdoc.who.int/trs/WHO_TRS_ 937_eng.pdf. 
3. Kalantzi L, Reppas C, Dressman JB, Amidon GL, Junginger HE, Midha KK, Shah VP, Stavchansky SA, Barends DM. 2006. Biowaiver monographs for immediate release solid oral dosage forms: Acetaminophen (paracetamol). J Pharm Sci 95:414.

4. Manzo RH, Olivera ME, Amidon GL, Shah VP, Dressman JB, Barends DM. 2006. Biowaiver monographs for immediate release solid oral dosage forms: Amitriptyline hydrochloride. J Pharm Sci 95: 966-973.

5. Verbeeck RK, Junginger HE, Midha KK, Shah VP, Barends DM. 2005. Biowaiver monographs for immediate release solid oral dosage forms based on biopharmaceutics classification system (BCS) literature data: Chloroquine phosphate, chloroquine sulfate, and chloroquine hydrochloride. J Pharm Sci 94:1389-1395.

6. Jantratid E, Prakongpan S, Dressman JB, Amidon GL, Junginger HE, Midha KK, Barends DM. 2006. Biowaiver monographs for immediate release solid oral dosage forms: Cimetidine. J Pharm Sci 95:974984.

7. Potthast H, Dressman JB, Junginger HE, Midha KK, Oeser H, Shah VP, Vogelpoel H, Barends DM. 2005. Biowaiver monographs for immediate release solid oral dosage forms: Ibuprofen. J Pharm Sci 94: 2121-2131.

8. Becker C, Dressman JB, Amidon GL, Junginger HE, Kopp S, Midha KK, Shah VP, Stavchansky S, Barends DM. 2006. Biowaiver monographs for immediate release solid oral dosage forms: Isoniazid. J Pharm Sci 96:522-531.

9. Vogt M, Derendorf H, Kramer J, Junginger HE, Midha KK, Shah VP, Stavchansky S, Dressman JB, Barends DM. 2007. Biowaiver monographs for immediate release solid oral dosage forms: Prednisolone. J Pharm Sci 96:27-37.

10. Vogt M, Derendorf H, Kramer J, Junginger HE, Midha KK, Shah VP, Stavchansky S, Dressman JB, Barends DM. 2007. Biowaiver monographs for immediate release solid oral dosage forms: Prednisone. J Pharm Sci 96:1480-1489.

11. Kortejarvi H, Yliperttula M, Dressman JB, Junginger HE, Midha KK, Shah VP, Barends DM. 2005. Biowaiver monographs for immediate release solid oral dosage forms: Ranitidine hydrochloride. J Pharm Sci 94:1617-1625.

12. National Libary of Medicine (NLM) and the National Institutes of Health, NCBI, PubMed. 2006. NCBI http://www.pubmed.gov.

13. National Libary of Medicine (NLM) NCBI PubChem Compound. http://www.ncbi.nlm.nih.gov/ entrez/query.fcgi? $\mathrm{db}=$ pccompound.

14. Medicines Complete. 2006. London: Pharmaceutical Press. http://www.medicinescomplete.com/mc/.

15. World Health Organization (WHO). Library \& Information Networks for Knowledge Database
(WHOLIS). http://dosei.who.int/uhtbin/cgisirsi/ Mon+Jan+10+13:45:18+MET+2005/0/49.

16. VIDAL BIAM database: Ethambutol Dichlorhydrate (French). http://www.biam2.org.

17. Rote Liste ${ }^{\mathbb{R}}$ Service GmbH Frankfurt/Main: ROTE LISTE $^{\mathbb{R}}$ Arzneimittelsverzeichnis für Deutschland (einschließlich EU-Zulassungen und bestimmter Medizinprodukte) (German). http://www.rote-liste. de/Online.

18. VIDAL L'information de référence sur les produits de santé (French). http://www.vidal.fr.

19. World Health Organization (WHO). 2004. The International Pharmacopoeia. In Third edition, General Methods of Analysis, Quality Specifications for Pharmaceutical Substances, Excipients and Dosage Forms. http://www.who.int/bookorders/anglais/detart1.jsp?sesslan=1 \& codlan=1 \& codcol $=15$ \& $\operatorname{codcch}=4091$.

20. World Health Organization (WHO). Guidance on INN. http://www.who.int/medicines/services/inn/ innquidance/en/.

21. World Health Organization (WHO). 2003. Revision approved June 2004. Treatment of Tuberculosis: Guidelines for national programmes. http:// www.emro.who.int/stb/media/pdf/Guidelines2003. pdf.

22. Martindale: The Complete Drug Reference, electronic version. 2006. London: Pharmaceutical Press. http://www.medicinescomplete.com/mc/martindale/2006/.

23. Goyal JL, De S, Singh NP, Bhatia A. 2003. Evaluation of visual functions in patients on ethambutol therapy for tuberculosis: A prospective study. J Commun Dis 35:230-243.

24. Griffith DE, Brown-Elliott BA, Shepherd S, McLarty J, Griffith L, Wallace RJ, Jr. 2005. Ethambutol ocular toxicity in treatment regimens for Mycobacterium avium complex lung disease. Am J Respir Crit Care Med 172:250-253.

25. Chan RY, Kwok AK. 2006. Ocular toxicity of ethambutol. Hong Kong Med J 12:56-60.

26. World Health Organization (WHO). 2004. Toman's Tuberculosis. Case Detection, Treatment and Monitoring. 2nd Edition. http://whqlibdoc.who.int/ publications/2004/9241546034.pdf. http://whqlibdoc. who.int/publications/2004/9241546034_1.pdf http://whqlibdoc.who.int/publications/2004/

9241546034_2.pdf http://whqlibdoc.who.int/publications/2004/9241546034 3.pdf http://whqlibdoc. who.int/publications/2004/9241546034_4.pdf

27. FATOL Fachinformation EMB Fatol ${ }^{\mathrm{B}}{ }^{-}$(German).

28. RIEMSER Fachinformation Myambutol ${ }^{\mathbb{R}}$ (German).

29. AHFS Drug Information, The American Society of Health-System Pharmacists (ASHP); electronic version. 2007. London: Pharmaceutical Press. http://www.medicinescomplete.com/mc/ahfs/ current/. 
30. Rubin-Preminger JM, Bernstein J, Harris RK, Evans IR, Gh PY. 2004. Variable temperature studies of a polymorphic system comprising two pairs of enatiotropically related forms: [S,S]-ethambutol dihydrochloride. Crystal Growth Design 4: 431-439.

31. Brewer GA. 1977. Analytical profiles of drug substances and excipients. Florey's K, Brittain HG, C editors. Oxford University Press. 6: 193-258.

32. Clarke's Analysis of Drugs and Poisons, Pharmaceutical Press, London: Electronic version. 2006. London: Pharmaceutical Press. http://www. medicinescomplete.com/mc/clarke/2006/.

33. Pharm Eur Kommentar (German), 20. Lieferung, Vol. 6: 2005.

34. Kasim NA, Whitehouse M, Ramachandran C, Bermejo M, Lennernas H, Hussain AS, Junginger HE, Stavchansky SA, Midha KK, Shah VP, Amidon GL. 2004. Molecular properties of WHO essential drugs and provisional biopharmaceutical classification. Mol Pharm 1:85-96.

35. World Health Organization (WHO). 2005. Essential Medicines WHO Model List (EML). 14th edition, (revised version march 2005) http://whqlibdoc.who. int/hq/2005/a87017_eng.pdf.

36. U.S. Department of Health and Human Services Food and Drug Administration, Center for Drug Evaluation and Research, Office of Pharmaceutical Science, Office of Generic Drugs: Electronic Orange Book, approved drug products with therapeutic equivalence evaluations; electronic source. 2006. NCBI http:/www.fda.gov/cder/ob/.

37. Lee CS, Brater DC, Gambertoglio JG, Benet LZ. 1980. Disposition kinetics of ethambutol in man. J Pharmacokinet Biopharm 8:335-346.

38. Place VA, Peets EA, Buyske DA, Little RR. 1966. Metabolic and special studies of ethambutol in normal volunteers and tuberculous patients. Ann N Y Acad Sci 135:775-795.

39. Place VA. 1966. Laboratory and clinical studies. Ann N Y Acad Sci 135:683-685.

40. Dume T, Wagner C, Wetzels E. 1971. Pharmacokinetics of ethambutol in healthy individuals and in patients with terminal renal failure. Dtsch Med Wochenschr 96:1430-1434.

41. Peets EA, Sweeney WM, Place VA, Buyske DA. 1965. The absorption, excretion, and metabolic fate of ethambutol in man. Am Rev Respir Dis 91:51-58.

42. Lee CS, Gambertoglio JG, Brater DC, Benet LZ. 1977. Kinetics of oral ethambutol in the normal subject. Clin Pharmacol Ther 22:615-621.

43. Lee CS, Benet LZ. 1978. Micro and macro GLC determination of ethambutol in biological fluids. J Pharm Sci 67:470-473.

44. Kleber FX. 1979. Absorption of anti-tuberculous drugs after gastric surgery (author's transl). Prax Klin Pneumol 33:38-44.
45. Holdiness MR. 1984. Clinical pharmacokinetics of the antituberculosis drugs. Clin Pharmacokinet 9:511-544.

46. Holdiness MR. 1985. Chromatographic analysis of antituberculosis drugs in biological samples. J Chromatogr 340:321-359.

47. Christopher TG, Blair A, Forrey A, Cutler RE. 1973. Kinetics of ethambutol elimination in renal disease. Proc Clin Dial Transplant Forum 3:96101.

48. Peloquin CA, Bulpitt AE, Jaresko GS, Jelliffe RW, Childs JM, Nix DE. 1999. Pharmacokinetics of ethambutol under fasting conditions, with food, and with antacids. Antimicrob Agents Chemother 43: 568-572.

49. Mattila MJ, Linnoila M, Seppala T, Koskinen R. 1978. Effect of aluminium hydroxide and glycopyrrhonium on the absorption of ethambutol and alcohol in man. Br J Clin Pharmacol 5:161-166.

50. Ameer B, Polk RE, Kline BJ, Grisafe JP. 1982. Effect of food on ethambutol absorption. Clin Pharm 1:156-158.

51. Shepherd RG, Baughn C, Cantrall ML, Goodstein B, Thomas JP, Wilkinson RG. 1966. Structureactivity studies leading to ethambutol, a new type of antituberculous compound. Ann NY Acad Sci 135: 686-710.

52. Agrawal S, Singh I, Kaur KJ, Bhade SR, Kaul CL, Panchagnula R. 2002. Bioequivalence assessment of rifampicin, isoniazid and pyrazinamide in a fixed dose combination of rifampicin, isoniazid, pyrazinamide and ethambutol vs. separate formulations. Int J Clin Pharmacol Ther 40:474-481.

53. Ashokraj Y, Singh I, Kaur KJ, Kohli G, Bhade SR, Varma MV, Kaul CL, Panchagnula R. 2005. Establishment of a reference formulation for bioequivalence assessment of rifampicin-containing FDCs: An essential step towards improving tuberculosis treatment. Int J Tuberc Lung Dis 9:791796.

54. Panchagnula R, Sancheti P, Rungta S, Agrawal S, Kaul CL. 2003. Evaluation of bioequivalence of isoniazid and pyrazinamide in three and four drugs fixed dose combinations using WHO simplified protocol. Pharmacol Res 48:383-387.

55. Panchagnula R, Kaur KJ, Singh I, Kaul CL. 2000. Bioequivalence of rifampicin when administered as a fixed-dose combined formulation of four drugs versus separate formulations. Methods Find Exp Clin Pharmacol 22:689-694.

56. Gleiter CH, Gundert-Remy U. 1994. Bioinequivalence and drug toxicity. How great is the problem and what can be done? Drug Saf 11:1-6.

57. Gleiter CH, Klotz U, Kuhlmann J, Blume H, Stanislaus F, Harder S, Paulus H, Poethko-Muller C, Holz-Slomczyk M. 1998. When are bioavailability studies required? A German proposal. J Clin Pharmacol 38:904-911. 
58. U.S. Pharmacopeia (USP30- NRF25), 2088-9. 2007.

59. European Medicines Evaluation Agency (EMEA). 2001. Committee for Proprietary Medicinal Products (CPMP). Note for Guidance on the Investigation of Bioavailability and Bioequivalence. http:// www.emea.eu.int/pdfs/human/ewp/140198en.pdf.

60. U.S. Department of Health and Human Services Food and Drug Administration Center for Evaluation and Research (CDER). 2000. Guidances for industry: Waiver of in vivo bioavailability and bioequivalence studies for immediate-release solid oral dosage forms based on a Biopharmaceutics Classification System. http://www.fda.gov/CDER/GUIDANCE/3618fnl.pdf.

61. Wu CY, Benet LZ. 2005. Predicting drug disposition via application of BCS: Transport/absorption/ elimination interplay and development of a biopharmaceutics drug disposition classification system. Pharm Res 22:11-23.
62. Lindenberg M, Kopp S, Dressman JB. 2004. Classification of orally administered drugs on the World Health Organization Model list of Essential Medicines according to the biopharmaceutics classification system. Eur J Pharm Biopharm 58:265278.

63. WHO. 2006. Multisource (generic) pharmaceutical products: Guidelines on registration requirements to establish interchangeability, Technical Report Series, No937, 40th Report, Annex 7 of WHO Expert committee on specifications for pharmaceutical preparations. http://whqlibdoc.who.int/trs/ WHO_TRS_937_eng.pdf.

64. Zhu $\overline{\mathrm{M}}$, Burman WJ, Starke JR, Stambaugh JJ, Steiner P, Bulpitt AE, Ashkin D, Auclair B, Berning SE, Jelliffe RW, Jaresko GS, Peloquin CA. 2004. Pharmacokinetics of ethambutol in children and adults with tuberculosis. Int J Tuberc Lung Dis 8:1360-1367. 